\title{
AN EXPERIMENTAL EVALUATION OF THE INDICATOR DILUTION TECHNIQUE FOR THE MEASUREMENT OF MITRAL REGURGITATION *
}

\author{
By ROBERT H. EICH, INGOLF STAIB $†$ AND DANIEL ENERSON $\ddagger$ \\ (From the Department of Medicine and Surgery, State University of Nezv York, Upstate \\ Medical Center, Syracuse, N. Y.)
}

(Submitted for publication May 19, 1959; accepted July 23, 1959)

In the selection of patients for mitral commissurotomy, accurate assessment of the amount of mitral regurgitation on a clinical basis may be extremely difficult (1). Hence, the indicator dilution technique, which offers some possibility for detection and a quantification of the regurgitant flow, has been widely applied to this problem in patients (2-5). However, as much of the work has been done in patients in whom precise quantification of the amount of insufficiency was not possible, experimental proof of the value of the technique in detecting known amounts of regurgitation is lacking. For this reason it was felt to be important to evaluate the technique in an experimental preparation in which the regurgitant flow could be controlled and measured. To do this, regurgitation was produced in the open-chested dog by an external polyvinyl shunt between the left ventricle and the left auricle. With this preparation, multiple comparisons between curves obtained with the shunt open and closed could be made, the amount of regurgitation could be measured, and yet blood flow and volume were not artificially fixed as in a model.

\section{MATERIAL AND METHODS}

Twenty-five adult mongrel dogs weighing between 9 and $24 \mathrm{Kg}$. were studied. The data from 15 of the dogs were considered satisfactory and used in the study. Chloralose $50 \mathrm{mg}$. per $\mathrm{Kg}$. and urethane $500 \mathrm{mg}$. per $\mathrm{Kg}$. were used for anesthesia in all cases, and respiration was controlled using intermittent positive pressure with 100 per cent oxygen through a No. 32 endotracheal tube. The chest was opened through the left fifth interspace and the pericardium opened widely. A No. 7 Cournand catheter was introduced into the main pulmonary artery and polyvinyl catheters inserted into the left auricle and left ventricle.

* Presented in part before the American Federation for Clinical Research, May, 1958.

$\dagger$ Present address: II. Chirurg. Univ. Klinik, KolnMerheim/Rh., West Germany.

$\ddagger$ Department of Surgery.
Both catheters were $22 \mathrm{~cm}$. in length; the left auricular catheter was $1.2 \mathrm{~mm}$. internal diameter and $1.8 \mathrm{~mm}$. outer diameter, the ventricular catheter was $0.6 \mathrm{~mm}$. internal diameter and $1.0 \mathrm{~mm}$. outer diameter. Pressures were recorded using a Hathaway blood pressure control unit, Type MBC2 with variable inductance gauges and a Hathaway oscillograph, Type S-14-C. Pressures were recorded before the shunt was put in and before and after all cardiac output indicator dilution determinations, both with the shunt open and closed. Systolic, diastolic and mean pressures were measured for the left ventricle and the pulmonary artery, and mean pressure for the left auricle. Mean pressures were determined planimetrically in all cases.

The shunt consisted of a polyvinyl tube, $4 \mathrm{~mm}$. internal diameter and $31 \mathrm{~cm}$. long with a " $Y$ " tube in the middle, so that a side tube could be led off and attached to a reservoir. The shunt was introduced into the left auricle after the tip of the left auricular appendage had been removed; the other end was introduced into the left ventricle through a stab wound in the apex and both were fastened in by purse-string sutures. (Figure 1 shows the shunt in place.) To measure shunt flow, both limbs of the shunt, that is, to the left auricle and to the reservoir were unclamped, the reservoir was set at left auricular level and the limb leading into the auricle was clamped. Flow was then measured into the reservoir for 10 seconds or $50 \mathrm{ml}$. This amount of blood loss did not alter blood pressure and blood was immediately returned to the dog. Shunt flow was measured before and after all cardiac output determinations done with the shunt open. With this size shunt, the regurgitant flow varied between 20 and 38 per cent of the forward flow, forward flow being measured by the dye dilution technique.

Cardiac outputs were done using the dye dilution method of Stewart and Hamilton (6) with $5 \mu \mathrm{c}$. of radioactive iodinated human serum albumin in $0.5 \mathrm{ml}$. of saline as the indicator. The amount injected was determined by weighing the syringe before and after injection. For the left auricular (LA) injections, a saline-filled, $2 \mathrm{ml}$. capacity polyethylene tube was attached to the auricular catheter. This was filled with the indicator through one $\operatorname{limb}$ of a three-way stopcock, and then the contents rinsed in as rapidly as possible with a $10 \mathrm{ml}$. saline rinse through the other limb of the stopcock. Sample collection was begun with the start of the rinse which was considered zero time. The duration of the rinse was one to two seconds. Interrupted samples timed by a metronome were taken from the femoral artery at one second intervals using an $18 \mathrm{~cm}$. length of polyethylene tubing $(3 \mathrm{~mm}$. internal diameter 


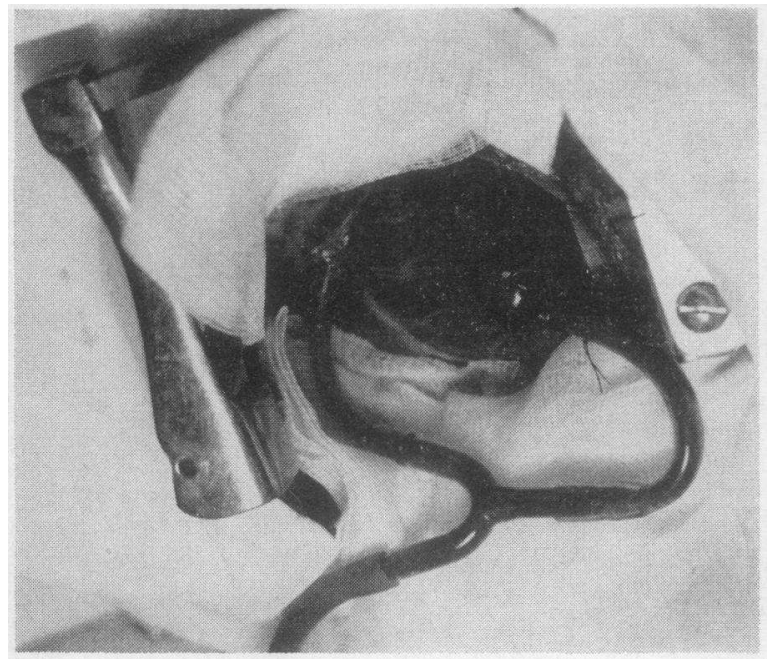

Fig. 1. Shunt in Place in the Dog

and total capacity $1.05 \mathrm{ml}$.) attached to an indwelling No. 18 Cournand needle. The duration of the sampling was 30 seconds and the volume of each sample varied between $0.5 \mathrm{ml}$. and $1 \mathrm{ml}$. Blood loss was replaced after each output, using blood from a donor dog obtained in advance. Five-tenths $\mathrm{ml}$. samples were pipetted into distilled water, mixed and counted in a well counter for one minute. Counts were then plotted on semi-log paper, the downslope extrapolated to 5 per cent of the peak concentration and the curve then replotted on linear graph paper so that the area of the curve could be calculated. Cardiac output was calculated by the usual Stewart-Hamilton formula (6); $\operatorname{COP}=\frac{\mathrm{I} 60}{\overline{\mathrm{c} t}}$, where $\mathrm{I}=$ amount injected in counts per minute, $\overrightarrow{\mathrm{c}}=$ mean concentration in counts per minute per liter, and $\mathrm{t}=$ time of curve. Slope was calculated from the formula $\frac{\log \text { e } C 1-\log \text { e } C 2}{\mathrm{~T} 2-\mathrm{T} 1}$, where $\mathrm{C} 1$ and $\mathrm{C} 2$ are concentrations in counts per minute per liter and $\mathrm{T} 1$ and $\mathrm{T} 2$ are the comparable times on the downslope of the curve. The concentrations, peak (PC), least (LC) and recirculation ( $R C)$, and the times, appearance time (AT), disappearance time (DT) and build-up time (BT) are those described by Wood and Swan (7). Their derivation is shown in Figure 2. Disappearance time was taken as the time from the peak concentration to 5 per cent of the peak concentration. Mean circulation time was calculated using the formula: M.C.T. $=\frac{\Sigma(\mathrm{CT})}{\overline{\mathrm{c}} \mathrm{t}}$, where $\mathrm{C}=$ counts per minute at time $\mathrm{T}, \mathrm{T}=$ time interval in seconds from the time of injection until the time at which $\mathrm{C}$ is measured, $\overline{\mathrm{c}}=$ mean concentration and $\mathrm{t}=$ time of curve.

Central blood volume was calculated as C.B.V. = $\frac{\text { M.C.T. X COP }}{60}$. Slope volume was calculated by the method of Newman and co-workers (8):

$$
\text { S.V. }=\frac{\text { cardiac output }(\mathrm{ml} . \text { per second })}{\text { slope }} .
$$

The sequence of the output measurements was varied, so that in some dogs an output was done first with the shunt open and repeated after the shunt had been clamped for 10 minutes, and in others the procedure was reversed. In six dogs duplicate measurements were made. In seven dogs the reproducibility of cardiac output measurements with the shunt open and using LA injection was studied using identical injections 10 minutes apart. In nine dogs, dye output determinations were also obtained by injection into pulmonary artery both with the shunt open and closed, to compare outputs from two different injection sites.

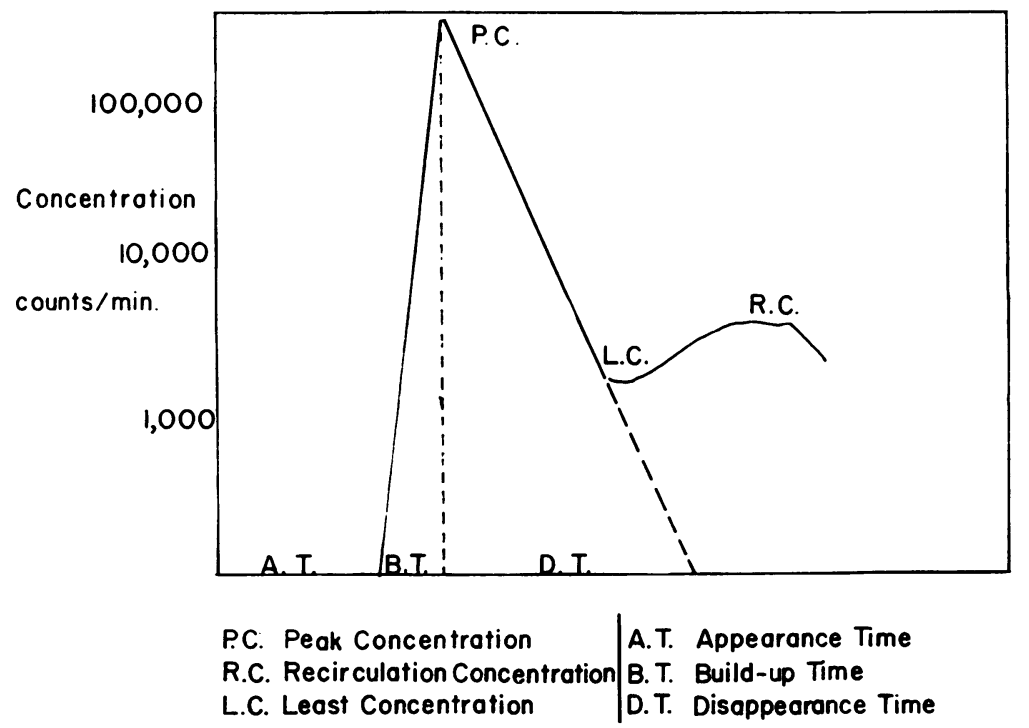

Fig. 2. Time and Concentration Components of the Dye Dilution Curve 
TABLE I

Data from dye dilution curves in 15 dogs

\begin{tabular}{|c|c|c|c|c|c|c|c|c|c|c|c|c|}
\hline \multirow[t]{3}{*}{$\begin{array}{l}\text { Dog } \\
\text { No. }\end{array}$} & \multicolumn{2}{|c|}{$\begin{array}{l}\text { Left atrial } \\
\text { pressure }\end{array}$} & \multicolumn{2}{|c|}{$\begin{array}{l}\text { Cardiac } \\
\text { output }\end{array}$} & \multicolumn{2}{|c|}{$\begin{array}{c}\text { Mean circulation } \\
\text { time }\end{array}$} & \multicolumn{2}{|c|}{$\begin{array}{c}\text { Central blood } \\
\text { volume }\end{array}$} & \multicolumn{2}{|c|}{ Slope } & \multicolumn{2}{|c|}{$\begin{array}{c}\text { Slope } \\
\text { volume }\end{array}$} \\
\hline & $m m$. & & & & & & & & & & & \\
\hline & O* & $\mathrm{C}^{*}$ & $\mathrm{O}$ & C & $\mathrm{O}$ & C & $\mathrm{O}$ & C & $\mathrm{O}$ & $\mathrm{C}$ & o & C \\
\hline 5 & 6 & 7 & 1.08 & 1.13 & 5.7 & 4.9 & 103 & 92 & 0.72 & 0.85 & 25 & 22 \\
\hline 6 & 8 & 6 & 0.94 & 1.03 & 10.1 & 10.0 & 158 & 180 & 0.49 & 0.49 & 32 & 26 \\
\hline 7 & 4 & 3 & 0.56 & 0.68 & 6.3 & 5.7 & 59 & 65 & 0.30 & 0.98 & 31 & 12 \\
\hline 8 & 7 & 6 & 1.20 & 1.38 & 7.5 & 7.7 & 151 & 178 & 0.56 & 0.79 & 36 & 29 \\
\hline 9 & & & 1.13 & 1.15 & 10.2 & 6.2 & 192 & 119 & 0.32 & 0.62 & 60 & 31 \\
\hline 10 & 9 & 6 & 0.90 & 0.73 & 6.4 & 7.1 & 96 & 87 & 0.35 & 0.54 & 42 & 22 \\
\hline 11 & 7 & 6 & 0.85 & 0.84 & 6.7 & 5.9 & 95 & 83 & 0.55 & 0.98 & 26 & 14 \\
\hline 16 & 4 & 3 & 1.56 & 1.33 & 9.1 & 9.9 & 236 & 230 & 0.59 & 0.81 & 44 & 27 \\
\hline 17 & 5 & 5 & 0.67 & 0.71 & 10.1 & 9.2 & 112 & 109 & 0.31 & 0.36 & 31 & 33 \\
\hline 19 & 5 & 6 & 1.06 & 1.03 & 12.8 & 11.0 & 226 & 188 & 0.33 & 0.49 & 54 & 35 \\
\hline 20 & 8 & 7 & 1.16 & 1.16 & 11.7 & 12.7 & 227 & 245 & 0.42 & 0.44 & 52 & 44 \\
\hline 21 & 2 & 1 & 1.50 & 1.40 & 7.2 & 7.6 & 180 & 177 & 0.47 & 0.64 & 53 & 36 \\
\hline 22 & 3 & & 2.46 & 2.87 & 7.7 & 6.7 & 316 & 322 & 0.54 & 0.73 & 78 & 65 \\
\hline 23 & 7 & 4 & 0.78 & 0.82 & 10.0 & 7.6 & 129 & 104 & 0.34 & 0.48 & 38 & 29 \\
\hline 24 & 4 & 3 & 2.5 & 2.3 & 8.3 & 7.9 & 345 & 286 & 0.49 & 0.59 & 78 & 68 \\
\hline Mean & 5.6 & 4.8 & 1.22 & 1.23 & 9.0 & 8.0 & 175 & 168 & 0.45 & 0.65 & 45 & 33 \\
\hline S. D. \pm & & & & & \pm 2.3 & 2.1 & 82 & 80 & 0.12 & 0.19 & 21 & 16 \\
\hline
\end{tabular}

* $\mathrm{O}=$ shunt open $; \mathrm{C}=$ shunt closed.

\section{RESULTS}

The basic data from the 15 dogs are shown in Tables I and II. In these tables, only the first set of outputs with the shunt open and closed was used. However, in six of the dogs multiple determinations were done and used in some of the statistical analyses. The simultaneous changes in pressure in the auricle and ventricle when the shunt was clamped are shown in Figure 3. In all cases there was an abrupt fall in left atrial pressure. Mean atrial pressure with the shunt open was $5.6 \mathrm{~mm}$. $\mathrm{Hg}$ and closed, $4.8 \mathrm{~mm}$. $\mathrm{Hg}$. The left ventricular pressure demonstrated an immediate rise with closing the shunt and shortly therefater a fall to the preclosure level. Cardiac

TABLE II

Data from dye dilution curves in 15 dogs

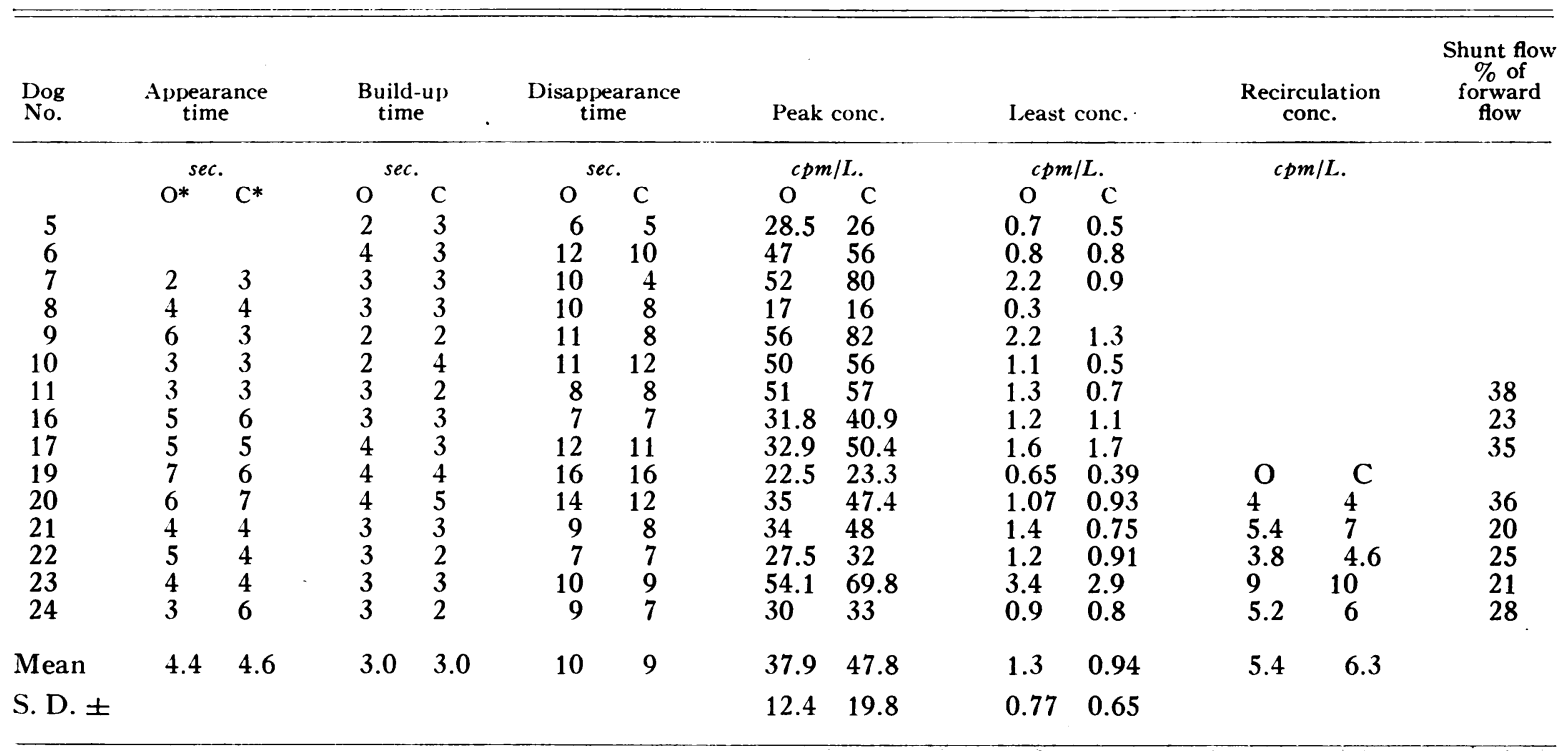

${ }^{*} \mathrm{O}=$ shunt open $; \mathrm{C}=$ shunt closed. 


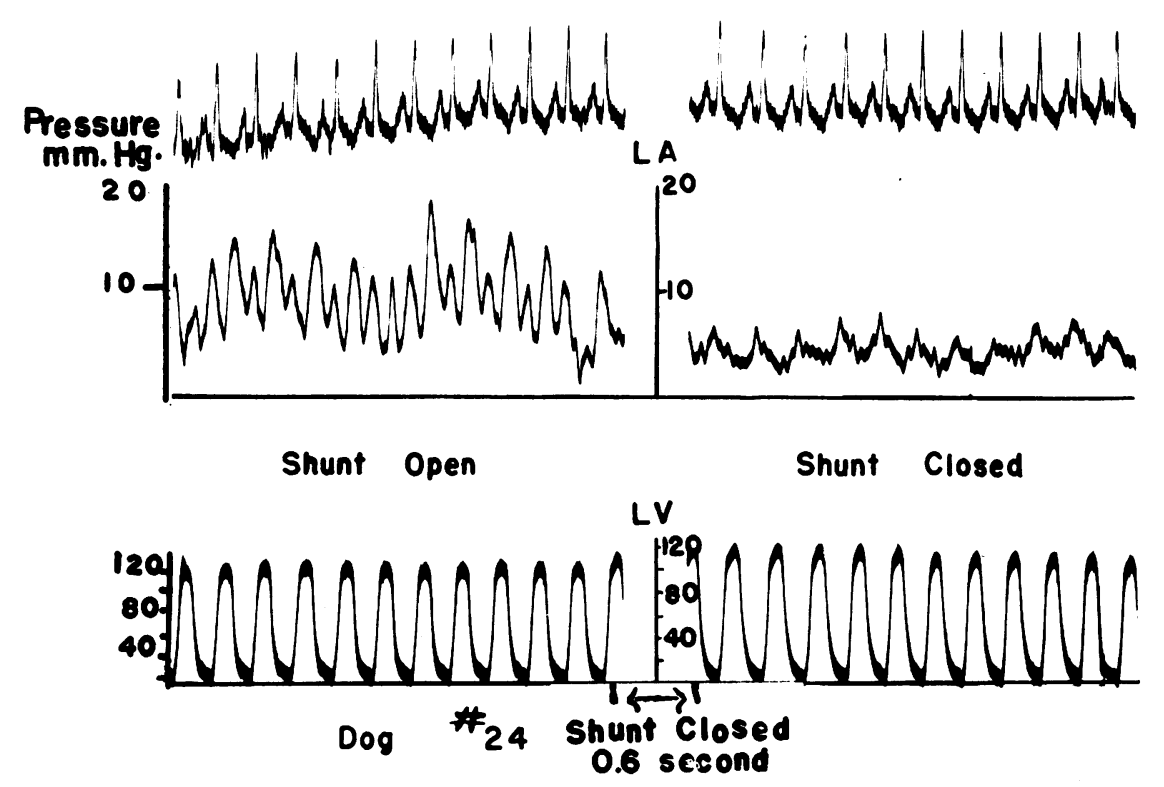

Fig. 3. Acute Changes in Left Auricular and Ventricular Pressure With Closing the Shunt

output with the shunt open and closed as measured by the dye dilution method was the same, the ratio of open to closed being 0.99 (S.D. \pm 0.12 ). In nine dogs, with the shunt open, the output obtained by injection into the pulmonary artery was

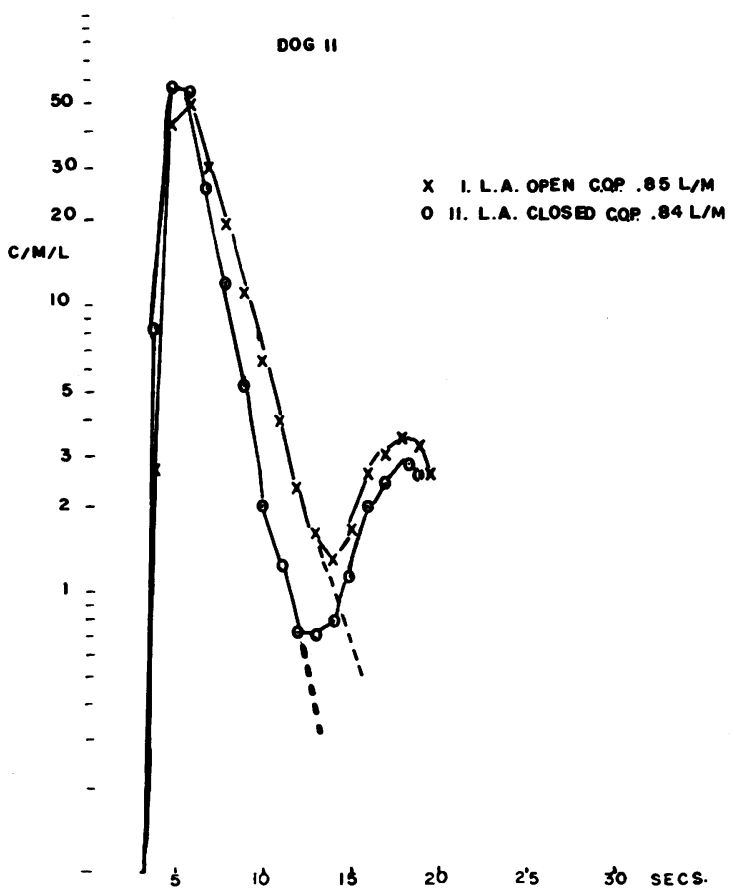

Fig. 4. Typical Dye Dilution Curves Obtained With the Shunt Open and Closed in Dog No. 11 compared to that from the left auricle. The mean ratio of pulmonary artery to left auricle was 0.89 (S.D. \pm 0.13 ). The reproducibility of the left auricular injection outputs was determined by two separate output measurements 10 minutes apart with the shunt open. The ratio of the first to the second output was 1.00 (S.D. \pm 0.18 ).

For all the dogs studied, the curve obtained with the shunt open could be easily separated from that with the shunt closed, by inspection. Two such typical curves are shown in Figure 4 . When the shunt was open, the downslope was prolonged, the disappearance time prolonged, the peak concentration less and the least concentration and recirculation concentration greater. Without the control, however, none of the measurements shown in Tables I and II would separate the curve obtained with the shunt open from that with the shunt closed. Likewise, no ratios involving time or concentration could be found which increased the degree of separation between the two groups. The results for several such ratios are shown in Figures 5 and 6 . The formulas used in the calculations are given in the figures except for the disappearance ratio. This is calculated from a concentration on the downslope at a time determined as the sum of build-up time plus peak concentration time, divided by the peak concentration. 
Forward output did not correlate with any of the time measurements, Figure $7,(r<0.2$ for all times) so that using output in the ratios did not increase the separation between open and closed measurements. Finally, no equation such as that suggested by Korner and Schillingford $(4,5)$ using both volume and flow could be developed. Their formula was a regression equation for the reciprocal of the downslope using cardiac output and central blood volume. There was no correlation between slope and cardiac output either with the shunt open or closed $(r=0.17$ closed and 0.29 open). Likewise, there was no correlation between slope and central blood volume $(r=0.177$ closed and 0.125 open), so that no such regression equation could be developed. Actually, the only correlations were between central blood volume and cardiac output $(\mathrm{r}=0.869$ closed and 0.838 open), and between slope volume and cardiac output ( $r=0.884$ closed and 0.790 open) which are inherent in the calculations. Finally, although the curve obtained with the shunt open could be separated from that with the shunt closed, by inspection, the difference between the two curves did not correlate with the per cent regurgitation so that even with a control, no quantification was possible.

\section{DISCUSSION}

The effect of valvular incompetence on the dye dilution curve has been extensively studied both in models and patients by several groups including Korner and Schillingford in England $(4,5)$ and Keys, Woodward, Swan, Burchell and Wood $(2,3)$ at the Mayo Clinic. In theory, the effect of incompetence would be to delay the washout of the indicator from the heart chambers and this can be well shown in models. For any given flow and volume, incompetence will prolong the downslope and lower the peak concentration. In patients, likewise, the effect of mitral insufficiency on the dye curve has been shown to be a prolongation of
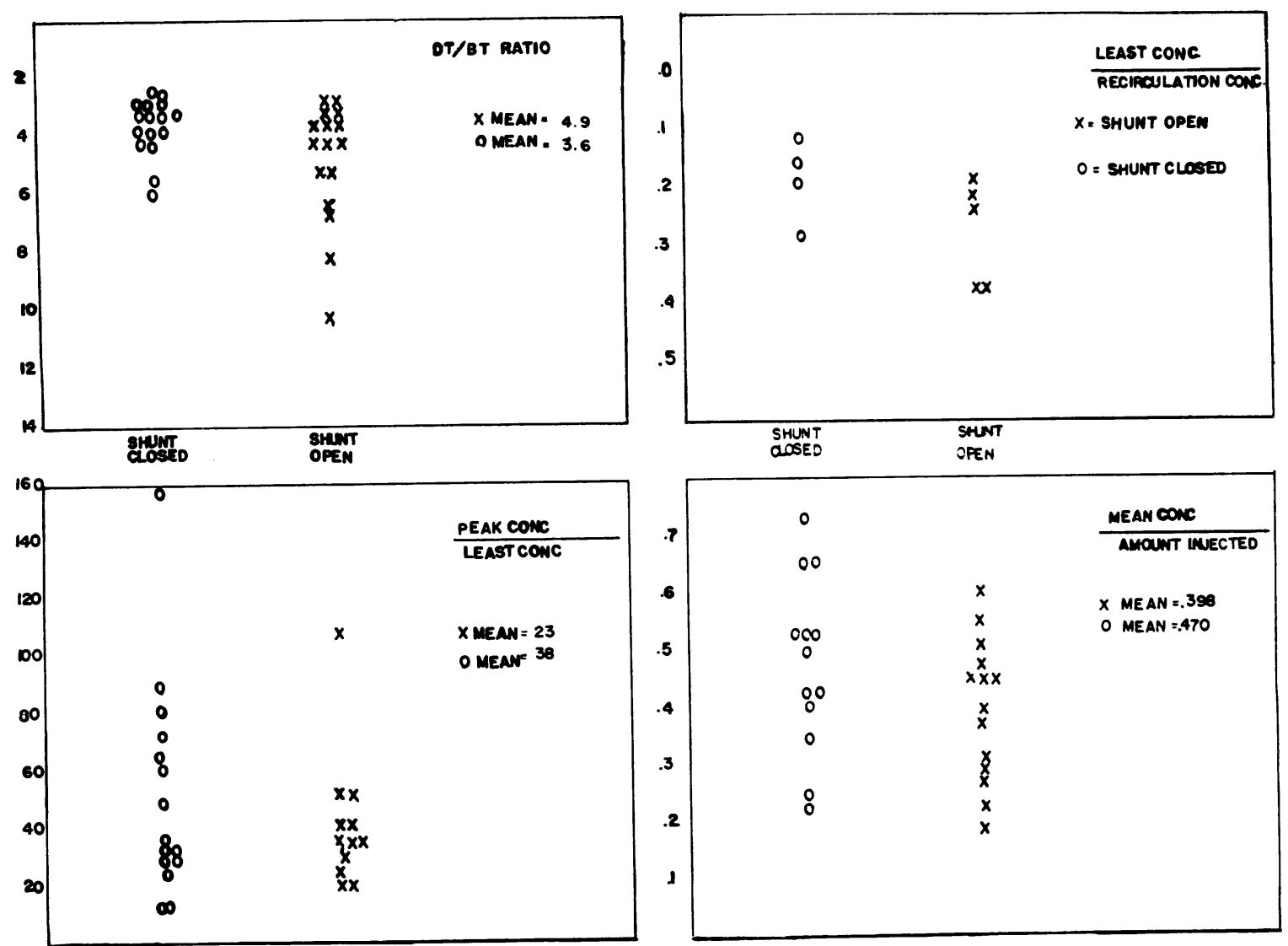

Fig. 5. Time and Concentration Ratios Derived From Dye Dilution Curves 

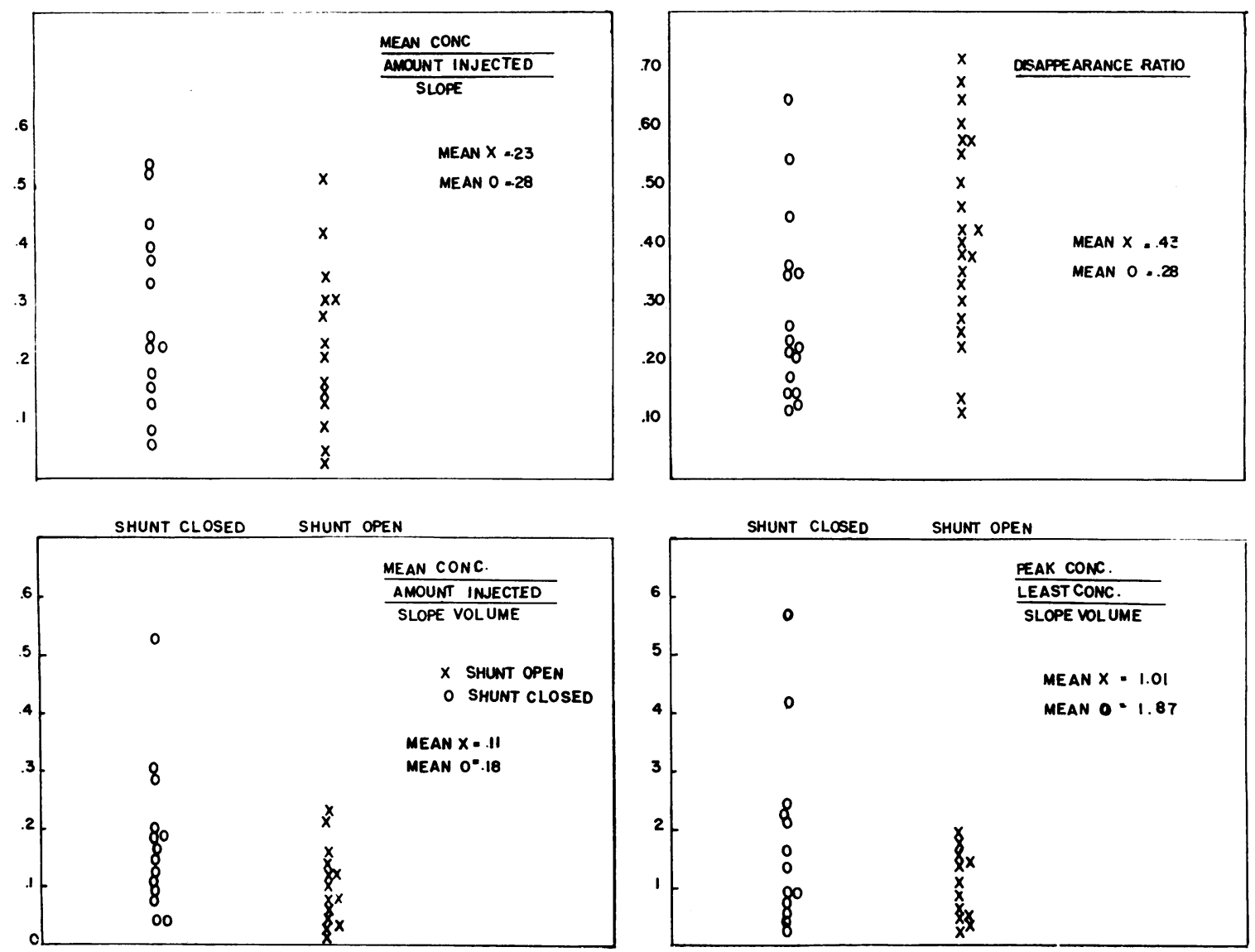

Fig. 6. Time and Concentration Ratios Derived From Dye Dilution Curves

the downslope and an increase in the ratio between least concentration and recirculation concentration, without affecting appearance time or mean circulation time. From this work, various calculations have been developed which, when applied to a dye curve, have been used to determine whether mitral regurgitation is present and in some cases to quantify the regurgitation. However, the dangers of applying model dye dilution studies to patients are very real (9) and in the patients studied, an accurate measurement of the amount of regurgitation for calibration of the technique may not be obtained, depending as it does on the surgeon's impression at operation. Therefore, it was believed to be important to evaluate the dye dilution technique in an experimental animal preparation in which the pitfalls of model work could be avoided.

It is, of course, true that acute studies in an experimental animal are not completely com- parable to a chronic clisease such as mitral insufficiency in man. The size relationship between the left auricle and ventricle is different, the shunt is not in the same position in relation to the flow through the ventricle as in an incompetent mitral valve, and the hemodynamics are altered by the chest being opened combined with an extensive surgical procedure. It was felt, however, that these disadvantages were offset by the opportunity to accurately control and measure the regurgitant flow and to obtain control and regurgitant dye curves in a system in which the variables of flow, volume and mixing were not artificially fixed.

A shunt of small dimensions was chosen in order to keep the regurgitant flow low so that the usefulness of the dye dilution technique could be evaluated in detecting small amounts of regurgitation. With this shunt the per cent of regurgitation varied between 20 and 38 per cent, which is said not to be significant regurgitation in terms of 
contraindication for mitral commissurotomy (1). This amount of regurgitation was sufficient, however, to elevate the left auricular pressure approximately $1 \mathrm{ml} . \mathrm{Hg}$ and on clamping the shunt, a transient rise in ventricular pressure was found which is similar to the finding of Wiggers and Feil (10).

Although most of the studies on the use of this dye dilution technique to measure mitral insufficiency have been done using a cuvette oximeter and a continuous recording system, the interrupted sample technique was chosen for this study. While the frequency response may not be comparable to a continuously recorded curve, it is a simple, well standardized technique to obtain a dye dilution curve (9). By this technique, satisfactory agreement between cardiac output using the pulmonary artery injection compared to left atrial injection was obtained, as well as satisfactory agreement between two left auricle injections done 10 minutes apart with the shunt open. Likewise, the effective cardiac output was the same with the shunt open or closed as measured by the dye technique, which has been shown to be true by Braunwald, Welch and Sarnoff, using a turbine flowmeter to measure output (11).

In spite of the small regurgitant flow chosen for the studies, the curve obtained with the shunt closed, which was used as a control, could always be separated from the curve taken with the shunt open by simple inspection of the two curves. The curve obtained with the shunt open always had a more prolonged downslope. Without a control, however, as can be seen by the wide range of values in Tables I and II, no separation could be obtained by slope or any other single measurement of time or concentration applied to the curve. It should be pointed out, however, that with one second sampling intervals, measurements of time components such as the build-up time, which
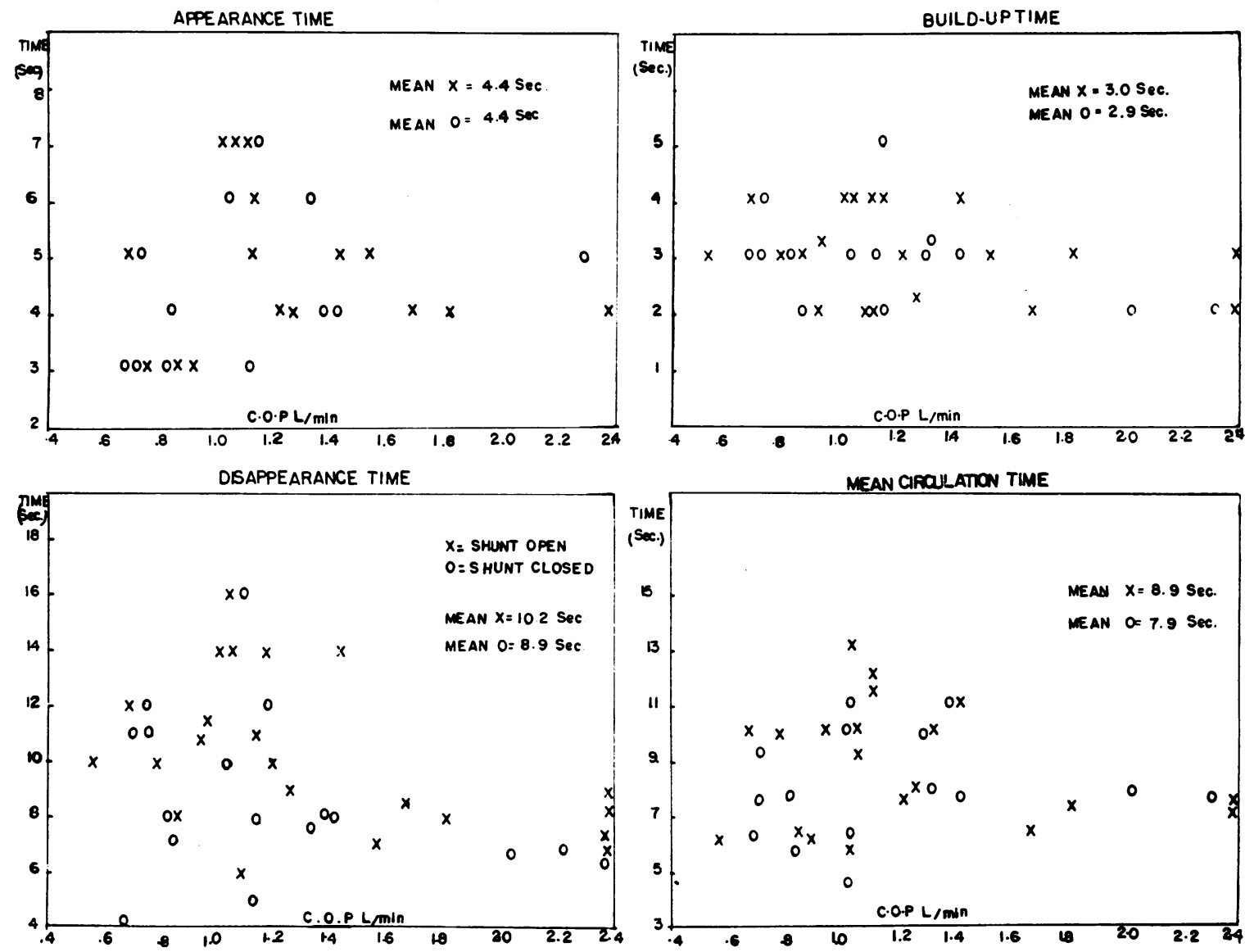

Fig. 7. The Relationship of Cardiac Output and the Time Components of the Dye Curves 
range from two to five seconds, are subject to large relative errors. Likewise, the measurement of specific points on the curve, such as the peak concentration, will be subject to error.

In theory, it might be expected that by combining two components of the curve which are altered in different directions by mitral regurgitation, a better separation could be obtained. For example, in regurgitation, the slope is prolonged so that the least concentration is increased while the recirculation concentration is decreased. The ratio of these two would thus be greater in mitral insufficiency than the changes in either one alone. Various ratios including the ratio of least to recirculation concentration were applied to the data as seen in Figures 5 and 6 , but the wide overlap was not appreciably altered and without a control curve, no useful separation could be obtained.

This scatter between values obtained either with the shunt open or closed is not unexpected since the characteristics of the dye curve are dependent on flow and volume as well, and these were variable from dog to dog. No calculation could be developed, using flow alone or flow and volume together, which would separate the open from the closed shunt. This would be expected from the data, since slope, which is the major parameter affected by regurgitation, did not correlate with cardiac output, either with the shunt open or closed. The wide scatter between determinations likewise makes quantification impossible even with a control curve.

The explanation for the inability of the dye curve to detect regurgitation without a control and for the inability to quantify even with a control, would appear to rest with factors such as volume and mixing which influence the contour of the curve and which cannot be accurately assessed at present. First, it is probably not possible to obtain an accurate measure of the blood volume of the auricle and ventricle by use of the StewartHamilton method (6). At best there is a 10 per cent methodical error in the calculation of central blood volume (12). Because of this, a meaningful correction for blood volume cannot be made. Secondly, variations in mixing either due to differences in injection or to the presence of laminar flow in the auricle or ventricle would affect the contour of the dye curve. It has been demonstrated by Woodward, Swan, Wood and Marshall
$(13,14)$ that such incomplete mixing may occur in the left auricle or left ventricle. Likewise, it has been shown by Hoffman and Rowe (15) in models, that the nature of the regurgitant jet and the chamber into which it enters, affect the indicator dilution curve. At present, no meaningful correction for these variations can be applied to the curve.

In spite of the variabilities, the fact remains that with a control curve rather small amounts of regurgitation can be detected by any simple analysis. In this experimental preparation, therefore, the validity of the dye dilution technique to demonstrate the presence of regurgitation seems well established. Whether the technique can be refined to quantify regurgitation remains to be studied.

\section{CONCLUSIONS}

1. The usefulness of the dye dilution technique for detecting mitral insufficiency in the range of 20 to 38 per cent of cardiac output was evaluated by means of an acute experimental preparation in 15 dogs.

2. With a control, the technique was good enough to detect small amounts of regurgitation.

3. Without a control, no calculation applied to the curve would separate the open from the closed shunt.

4. No quantification could be obtained even with a control.

5. Reasons for this wide overlap rest with variations in volume, mixing and washout, which cannot be assessed at present.

\section{REFERENCES}

1. McDonald, L., Dealy, J. B., Rabinowitz, M., and Dexter, L. Clinical, physiological and pathological findings in mitral stenosis and regurgitation. Medicine 1957, 36, 237.

2. Keys, J. R., Woodward, E., Jr., Swan, H. J. C., Burchell, H. B., and Wood, E. H. Recognition and quantitation of valvular insufficiency from indicator dilution curves (abstract). Circulation 1956, 14, 960.

3. Woodward, E., Jr., Burchell, H. B., and Wood, E. H. Dilution curves associated with valvular regurgitation. Proc. Mayo. Clin. 1957, 32, 518.

4. Korner, P. I., and Schillingford, J. P. The quantitative estimation of valvular incompetence by dye dilution curves. Clin. Sci. 1955, 14, 553. 
5. Korner, P. I., and Schillingford, J. P. Further observations on the estimation of valvular incompetence from indicator dilution curves. Clin. Sci. 1956, 15, 417.

6. Kinsman, J. M., Moore, J. W., and Hamilton, W. F. Studies on the circulation. I. Injection methodPhysical and mathematical considerations. Amer. J. Physiol. 1929, 89, 322.

7. Wood, E. H., and Swan, H. J. C. Definition of terms and symbols for description of circulatory indicator dilution curves. J. appl. Physiol. 1954, 6, 797.

8. Newman, E. V., Merrill, M., Genecin, A., Monge, W. R., and McKeever, W. P. The dye-dilution method for describing the central circulation-An analysis of factors shaping the time-concentration curves. Circulation 1951, 4, 735.

9. Dow, P. Estimations of cardiac output and central blood volume by dye dilution. Physiol. Rev. 1956, 36, 77.

10. Wiggers, C. J., and Feil, H. The cardio-dynamics of mitral insufficiency. Heart 1921-22, 9, 149.
11. Braunwald, E., Welch, G. H., Jr., and Sarnoff, S. J. Hemodynamic effects of quantitatively varied experimental mitral regurgitation. Circulat. Res. $1957,5,639$.

12. Doyle, J. T., Wilson, J. S., Lepine, C., and Warren, J. V. An evaluation of the measurement of cardiac output and of the so-called pulmonary blood volume by the dye-dilution method. J. Lab. clin. Med. 1953, 41, 29.

13. Woodward, E., Jr., Swan, H. J. C., and Wood, E. H. Evaluation of a method for detection of mitral regurgitation from indicator-dilution curves recorded from the left atrium. Proc. Mayo Clin. 1957, 32, 525.

14. Marshall, H. W., Woodward, E., Jr., and Wood, E. H. Hemodynamic methods for differentiation of mitral stenosis and regurgitation. Amer. J. Cardiol. 1958, 2, 24.

15. Hoffman, J. I. E., and Rowe, G. G. Some factors affecting indicator dilution curves in the presence and absence of valvular incompetence. J. clin. Invest. 1959, 38, 138. 